\title{
Twenty-first century changes in snowfall climate in Northern Europe in ENSEMBLES regional climate models
}

\section{Räisänen, Jouni}

2016-01

Räisänen , J 2016 , ' Twenty-first century changes in snowfall climate in Northern Europe in ENSEMBLES regional climate models ' , Climate dynamics : observational, theoretical and computational research on the climate system , vol. 46 , no. 1-2, pp. 339-353 . https://doi.org/10.1007/s00382-015-2

http://hdl.handle.net/10138/173355

https://doi.org/10.1007/s00382-015-2587-0

acceptedVersion

Downloaded from Helda, University of Helsinki institutional repository.

This is an electronic reprint of the original article.

This reprint may differ from the original in pagination and typographic detail.

Please cite the original version. 


\title{
21st century changes in snowfall climate in Northern Europe in ENSEMBLES regional climate models
}

Jouni Räisänen

Department of Physics, University of Helsinki, Finland

Submitted to Climate Dynamics, 8 December 2014

Revised, 23 March 2015

\author{
Corresponding author \\ Jouni Räisänen \\ Department of Physics, P.O. Box 48 (Erik Palménin aukio 1), \\ FI-00014 University of Helsinki, Finland \\ Phone +358-2941 50872; Fax + 358-2941 48802 \\ Email: jouni.raisanen@helsinki.fi
}




\section{Abstract}

2 Changes in snowfall in northern Europe $\left(55-71^{\circ} \mathrm{N}, 5-35^{\circ} \mathrm{E}\right)$ are analysed from 12

3 regional model simulations of 21st century climate under the Special Report on

4 Emissions Scenarios A1B scenario. As an ensemble mean, the models suggest a

5 decrease in the winter total snowfall in nearly all of northern Europe. In the

6 middle of the winter, however, snowfall generally increases in the coldest areas.

7 The borderline between increasing and decreasing snowfall broadly coincides

8 with the $-11^{\circ} \mathrm{C}$ isotherm in baseline (1980-2010) monthly mean temperature,

9 although with variation between models and grid boxes. High extremes of daily

10 snowfall remain nearly unchanged, except for decreases in the mildest areas,

11 where snowfall as a whole becomes much less common. A smaller fraction of the

12 snow in the simulated late $21^{\text {st }}$ century climate falls on severely cold days and a

13 larger fraction on days with near-zero temperatures. Not only do days with low

14 temperatures become less common, but they also typically have more positive

15 anomalies of sea level pressure and less snowfall for the same temperature than in

16 the present-day climate.

17

18 KEYWORDS: climate change, climate projection, snowfall, extreme snowfall,

19 regional climate model, ENSEMBLES, northern Europe 


\section{1. Introduction}

23 Snowfall and snow affect human activities in several ways. The winter snowpack

24 acts as a reservoir of water, thus delaying the release of precipitation to the soil

25 and alleviating drought in areas with modest summer precipitation. Snow also

26 provides opportunities for winter sports, and the light reflected by snow enhances

27 illumination in high-latitude areas where sunlight is scarce in midwinter. On the

28 other hand, snow frequently becomes a complication or even a hazard for many

29 forms of traffic, particularly when a lot of it falls in a short time. The slippery

30 conditions created by snow and ice increase both car accidents (Eisenberg and

31 Warner 2005) and falling injuries of pedestrians (Rális 1981, Karlsson 2014).

32 Snow also tends to be a major culprit of delays in railway traffic, as discussed for

33 Finnish conditions by Lehtonen (2015). These problems can be reduced by

34 ploughing snow off from roads, sidewalks and trails soon after it falls. However, a

35 trade-off exists between the cost of the ploughing capacity maintained and its

36 ability to eliminate disruption after major snowfall events. When planning

37 adaptation to a changing climate, information is thus required on changes in the

38 amount and characteristics of snowfall.

40 Projections of $21^{\text {st }}$ century greenhouse gas induced climate change in high 41 northern latitudes in winter indicate a substantial warming combined with an 42 increase in precipitation (e.g. Collins et al. 2013). These changes have opposing 43 effects on snow conditions, but their relative importance depends on the baseline 44 climate. In areas currently characterized by slightly sub-zero winter mean 45 temperatures, the frequency of positive temperatures increases steeply with 46 warming, strongly promoting decreases in snowfall and snow amount. In regions 47 with a much colder present-day climate, however, temperatures in winter will 48 largely remain below zero even after a moderate warming. There, changes in 49 snow conditions are more likely to be dominated by the increase in precipitation.

51 The relative importance of temperature and precipitation changes also depends on

52 the aspect of snow climate considered (Räisänen 2008, Krasting et al. 2013, 53 Kapnick and Delworth 2013). The amount of snow on ground in late winter is 54 strongly sensitive to warming, because the increased occurrence of above-zero 
55 temperatures both reduces the fraction of precipitation that falls as snow and 56 enhances mid-winter melting of snow. In the Coupled Model Intercomparison 57 Project third phase (CMIP3) simulations of $21^{\text {st }}$ century climate under the Special 58 Report on Emissions Scenarios (SRES) A1B scenario (Nakićenović and Swart 59 2000), Räisänen (2008) found the March mean snow water equivalent (SWE) to 60 increase only in the coldest areas. The borderline between increasing and 61 decreasing SWE broady coincided with the $-20^{\circ} \mathrm{C}$ isotherm in the present-day 62 November-to-March (NDJFM) mean temperature. However, increases in snowfall 63 are likely to cover a much wider area. In the CMIP5 simulations for the 64 Representative Concentration Pathways RCP4.5 scenario (van Vuuren et al. 65 2011), increases in seasonal mean snowfall tend to dominate when and where 66 present-day mean temperatures are below $-10^{\circ} \mathrm{C}$ (Krasting et al. 2013).

68 Changes in extreme daily snowfall might differ from those in the mean snowfall. 69 Reflecting the higher moisture holding capacity of warmer air, climate models 70 project a widespread increase in precipitation extremes on daily time scales, even 71 in some areas where the mean precipitation decreases (Seneviratne et al. 2012). 72 On the other hand, precipitation only falls as snow when it is cold enough. In 73 climate models as well as in reality (O' Gorman 2014), the heaviest snowfall 74 events occur when the surface air temperature is close to or slightly below zero. 75 This intuitively suggests that, in areas where such temperatures are common both 76 at present and in the future, the statistics of extreme snowfall should not change 77 very much. Yet, in sufficiently cold (mild) areas, the warming of climate should 78 increase (decrease) the frequency of marginally negative temperatures, thus 79 leading to an increase (decrease) in extreme snowfall. O' Gorman (2014) put 80 these expectations in a more quantitive form, and showed that they largely hold 81 when statistics of extreme snowfall in the CMIP5 simulations are aggregated over 82 the Northern Hemisphere land areas. A key result of his analysis is that increases 83 in snowfall extremes will extend to milder areas than increases in mean snowfall.

85 Räisänen and Eklund (2012, hereafter RE) studied projected $21^{\text {st }}$ century changes 86 in snow climate in northern Europe $\left(55-71^{\circ} \mathrm{N}, 5-35^{\circ} \mathrm{E}\right)$, using 11 regional climate 87 model (RCM) simulations from the ENSEMBLES (Ensembles-Based Predictions 88 of Climate Changes and Their Impacts; van der Linden and Mitchell 2009) 
89 project. They found the ensemble-averaged March mean SWE to decrease nearly

90 everywhere in the area, as expected for its relatively mild temperature regime,

91 although increases were simulated in the coldest parts in some of the individual

92 models. They also reported an increase in ensemble mean snowfall over the

93 Scandinavian mountains and much of Lapland in the NDJFM season, but a

94 decrease in milder areas and in the autumn and spring months. The ENSEMBLES

95 data set has two advantages compared with global climate models: the relatively

96 high $(25 \mathrm{~km})$ resolution which allows the regional topography and land-sea

97 distribution to be better described, and a more realistic present-day temperature

98 climate. Most global climate models, particularly those in CMIP3, simulate too

99 cold winter temperatures in northern Europe (Räisänen and Ylhäisi 2014) and

100 therefore probably underestimate the vulnerability of snow to warming of climate.

102 Here, we extend the analysis of RE by providing a more detailed assessment of

103 the snowfall projections. In particular, we investigate statistics of daily snowfall in

104 the ENSEMBLES simulations, focusing on heavy-to-extreme events that have the

105 largest impact on society. Will there be more or less heavy snowfall in northern

106 Europe in the future? How will the seasonality of heavy snowfall events change?

107 We also explore the relationship between temperature and snowfall in some detail.

108 How do the projected changes in mean and extreme snowfall in northern Europe

109 depend on the baseline temperatures? Can the changes in snowfall climate be

110 explained directly by the changing distribution of daily temperatures, or are there

111 other factors in play?

112

113 We first introduce the data sets used in Section 2. In Section 3, we start with an

114 overview of the ensemble mean changes in winter climate and particularly

115 snowfall statistics in the ENSEMBLES simulations, and then proceed to discuss

116 the differences between the individual models and the seasonality of the simulated

117 changes. In the end of Section 3, the relationships between temperature and

118 snowfall are studied from several angles. The conclusions are given in Section 4.

\section{2. Data sets}

120 We use 12 ENSEMBLES RCM simulations, including the 11 used in RE and one 121 (CNRM-A in the list given in Table 1) that has become available later. All these 
122 simulations were run at $25 \mathrm{~km}$ horizontal resolution using the SRES A1B scenario

123 and cover at least the years 1961-2099. In terms of the $\mathrm{CO}_{2}$ emissions and 124 projected global warming, SRES A1B is a medium-to-high scenario, slightly 125 exceeding the second highest of the recently adopted RCP scenarios, RCP 6.0 126 (Rogelj et al. 2012). The ensemble holds data from nine RCMs driven by 127 boundary data from six GCMs, counting the three global and regional climate 128 model versions from the HadCM3/HadRM3 perturbed-parameter ensemble 129 (Collins et al. 2010) separately (Table 1). For the common analysis, all the RCM 130 simulations were regridded to a regular $0.25^{\circ} \times 0.25^{\circ}$ latitude-longitude grid. 131 When analyzing the climate changes simulated by the models, we mostly focus on 132 the differences between a recent baseline period including 30 full winters (August 1331980 - July 2010) and a 30-year period in the end of this century (August 2069 134 July 2099), but also show some results for an intermediate future period (August 1352025 - July 2055).

137 Unweighted 12-simulation means (referred to as ensemble means) are used to 138 characterize the typical behaviour of the models. Due to the strong dependence of 139 RCM-simulated climates on the driving GCM (Räisänen et al. 2004; Déqué et al. 140 2007), an equally justified alternative would be to give the same total weight for 141 each group of RCM simulations driven by the same GCM. The difference

142 between these options was found to be unimportant for our general conclusions.

144 To evaluate how well the model results for the baseline period agree with the 145 observed climate, we use station-based gridded $\left(0.25^{\circ}\right.$ latitude $\times 0.25^{\circ}$ longitude $)$ 146 analyses of daily temperature, precipitation and sea level pressure from the E147 OBS v10.0 data set (Haylock et al. 2008, van den Besselaar et al. 2011). Daily 148 snowfall is not directly verifiable against observations, but for Fig. 7 in Section 3. 1496 we derive a rough estimate by assuming that the fraction of solid precipitation in 150 the real world has the same temperature dependence as on the average simulated 151 by the models, which include both snowfall and total precipitation in their output.

153 Some parts of our analysis focus on two specific regions, denoted as Lapland and 154 southern Finland (see top-left panel in Fig. 1). Lapland is the coldest part of 155 Fennoscandia, and is defined here as the area where the ensemble-averaged 
156 NDJFM mean temperature is below $-10^{\circ} \mathrm{C}$. Southern Finland, encompassing a belt

157 between the south coast of Finland and latitude $61^{\circ} \mathrm{N}$, exemplifies an area with a

158 milder climate. This region encompasses nearly half of the Finnish population

159 (Tilastokeskus 2014), and it has recently experienced several snowy winters that

160 caused disruption in road and train traffic particularly in the greater Helsinki area

161 (Lehtonen 2015). Although much smaller in area than Lapland (957 grid boxes,

$162281000 \mathrm{~km}^{2}$ ), Southern Finland (77 grid boxes, $29000 \mathrm{~km}^{2}$ ) is still reasonably

163 well resolved in the ENSEMBLES RCMs.

\section{Results}

\subsection{Ensemble mean changes in winter climate}

167 An overview of the simulated changes in winter climate is given in Fig. 1, using

168 the 12-model means to characterize typical model behavior. For reference, the 169 ensemble mean baseline values are given in the first column. For temperature and 170 precipitation, we select NDJFM to characterize the main snowfall season, 171 although some snow also falls before and after this season, particularly in the 172 north. In Southern Finland (Lapland), on the average 89\% (67\%) of the simulated 173 annual snowfall in 1980-2010 occurs in NDJFM.

175 The average model-simulated temperature replicates the observed NDJFM mean 176 temperature relatively well, although with a slight cold bias in most areas (not 177 shown). In Southern Finland (Lapland), the average bias relative to E-OBS is $1780.8^{\circ} \mathrm{C}\left(-1.4^{\circ} \mathrm{C}\right)$. For NDFJM precipitation, the agreement with the observations is 179 worse, with the simulated values exceeding the E-OBS estimate in most areas 180 except for western Norway. In Southern Finland (Lapland), the average bias is $18126 \%(52 \%)$. However, as discussed by RE, a large part of this discrepancy may 182 result from undercatch of (particularly solid) precipitation by rain gauges together 183 with their uneven spatial distribution. Despite the apparent positive bias in 184 precipitation, RE found a good agreement between ensemble mean simulated and 185 observation-based estimates of SWE in Finland, although with large variation 186 between the individual models (their Figs. 2 and 3e). Also note that these mean 187 values include one model (DMI-E5) which simulates substantially more 
188 precipitation than the others. Without DMI-E5, the ensemble mean precipitation

189 bias is reduced to $19 \%$ (46\%) in Southern Finland (Lapland).

191 By the years 2069-2099, the ensemble-averaged NDJFM mean temperature 192 increases by $3-6^{\circ} \mathrm{C}$, with the smallest warming in southwestern Scandinavia and 193 the largest warming in northeastern Lapland. The NDJFM precipitation increases 194 by $20-30 \%$ in much of Sweden and Finland, but less in most of Norway and near 195 the Baltic Sea coastlines. The changes from 1980-2010 to 2025-2055 share largely 196 the same geographical patterns but are typically at most a half of the changes 197 simulated by 2069-2099.

199 The total annual snowfall is largest over the Scandinavia mountains, where low 200 temperatures are combined with abundant precipitation $\left(3^{\text {rd }}\right.$ row of Fig. 1). In 201 Finland and Sweden, in particular, the northward increase in winter length and 202 severity dominates over the northward decrease in total precipitation, resulting in 203 more snowfall in the north than in the south. During the $21^{\text {st }}$ century, the 204 ensemble-averaged mean annual snowfall decreases nearly everywhere in 205 northern Europe, excluding a few grid boxes over the northern Scandinavian 206 mountains. This differs from Fig. 4 of RE, which showed a much wider area of 207 increasing NDJFM snowfall in northern Fennoscandia. The decrease in annual 208 snowfall where the NDJFM snowfall increases results from decreases before 209 November in the autumn and after March in the spring.

211 As an indicator of snowfall extremes, the average annual (August to July) 212 maximum one-day snowfall is shown in the bottom row of Fig. 1. The highest 213 values, up to $50 \mathrm{~mm}$ water equivalent (WE), again occur over the Scandinavian 214 mountains, but the general northward increase is smaller than for the total annual 215 snowfall. A local maximum stands out at the east coast of Sweden. This is an area

216 known for its occasionally extreme snowstorms, which are caused by mesoscale 217 snow bands that form in a cold northeasterly air flow over an ice-free Gulf of 218 Bothnia in early winter (Andræ 2002, Savijärvi 2012). During the $21^{\text {st }}$ century, the 219 one-day snowfall maxima are clearly reduced in the mildest areas, such as the 220 west coast of Norway and southern Sweden, but they still decrease less than the 221 total annual snowfall. Elsewhere, the changes in maximum snowfall remain 
222 mostly within $\pm 10 \%$ even in the end of the century, with slight increases in much

223 of the inland.

225 The decrease in annual total snowfall is due to a reduced number of snowfall

226 days, rather than smaller snowfall amounts in these days. While the frequency of 227 days with proper snowfall (at least $1 \mathrm{mmWE}$ ) decreases everywhere in northern 228 Europe, the average snowfall intensity for this group of days actually increases 229 slightly in most of the area (Fig. 2). In western Norway, snowfall intensity 230 decreases, but much less than snowfall frequency.

232 A closer view of the upper end of the daily snowfall distribution in Southern 233 Finland and Lapland is given in Fig. 3. The left panels represent the intensities of 234 the strongest 500 one-day snowfall events in the years 1980-2010, as averaged 235 over all grid boxes in the two areas. In terms of the ensemble mean snowfall 236 intensity in 1980-2010, this covers in southern Finland a range from 4 to 25 $237 \mathrm{mmWE}$ (the $500^{\text {th }}$ strongest and the strongest event, respectively) and in Lapland 238 a range from 6 to $34 \mathrm{mmWE}$, although with large variation between the individual 239 simulations. The average annual maxima, as used in Fig. 1, approximately 240 correspond to the $18^{\text {th }}$ event in both areas.

242 Reflecting the overall decrease in the number of snowfall days from 1980-2010 to 243 2069-2099, an ensemble mean decrease of 20-45\% occurs in the intensity of the $244100^{\text {th }}$ to $500^{\text {th }}$ ranked (i.e. 3 to 17 cases per year) snowfall events in Southern 245 Finland. However, the change becomes less negative towards the extreme upper 246 end, with virtually no difference in the intensity of the strongest 5 events between 247 1980-2010 and 2069-2099. In Lapland, the ensemble-averaged intensities in the 248 two periods are nearly identical (within $\pm 2 \%$ ) for the strongest 150 events, but a 249 slight decrease is found for weaker events. The near lack of change in the 250 strongest extremes, as found in both areas, concurs well with the average behavior 251 of the CMIP5 models over the Northern Hemisphere continents (O'Gorman 252 2014).

\subsection{Variation between individual models}

254 Table 2 shows the changes in time and area mean annual snowfall and annual 
256 individual models. Although a sample of 12 simulations is insufficient for a full

257 uncertainty analysis (particularly as many of them were made using the same

$258 \mathrm{RCM}$ or the same driving GCM), the variation of these projections gives some 259 information on their reliability. On the other hand, the apparent sensitivity of the

260 snow and snowfall projections on the baseline temperature climate (Fig. 1 and the 261 studies cited in the introduction) raises the question whether the range of the

262 simulated changes might have been amplified by baseline temperature biases in

263 some individual models. Therefore, Table 2 also includes the 1980-2010 mean

264 NDJFM temperatures, as well as the projected temperature and precipitation 265 changes.

267 The mean annual snowfall decreases from 1980-2010 to 2069-2099 in all 12 268 models, by $27-59 \%$ in Southern Finland and 7-29\% in Lapland (Table 2). The 269 average annual maximum one-day snowfall decreases in Southern Finland by 5$27020 \%$, excluding a $12 \%$ increase in SMHI-H3. In Lapland, the changes are small in 271 all models, with a range of $-10 \%$ to $9 \%$. Towards the extreme end of the 272 distribution, the variation between the models increases, particularly in Southern

273 Finland (Fig. 3). The smaller intermodel variation in changes of extreme snowfall 274 in Lapland reflects the larger averaging domain, which makes the area mean 275 statistics less sensitive to individual snowstorms.

277 The changes in both the mean and maximum snowfall tend to grow more negative 278 with increasing baseline NDJFM mean temperature. This intermodel correlation 279 follows physical expectations, but is only statistically significant for the mean 280 snowfall in Lapland and maximum snowfall in southern Finland (bottom of Table 281 2). In any case, the SMHI-BCM simulation with the coldest 1980-2010 NDJFM 282 mean temperature in Lapland also shows the smallest decrease in mean snowfall 283 in this area. Similarly, in Southern Finland SMHI-H3 stands out as the model with 284 the coldest baseline climate, the smallest decrease in mean snowfall, and an 285 increase in maximum snowfall that contradicts the other 11 projections. Yet, 286 METO-H3, ETCHZ-H0 and METO-H0 have nearly as low baseline temperatures 287 in Southern Finland as SMHI-H3, but simulate snowfall changes much closer to 288 the ensemble mean. Another potential contributor to the atypical snowfall changes 289 in SMHI-H3 in southern Finland is atmospheric circulation. The change in mean 
290 sea level pressure in SMHI-H3 suggests a slight increase in southerly flow that is

291 more favorable for snowfall in southern Finland than a slight increase in westerly 292 flow that is present in most of the other simulations (not shown). The tendency of

293 SMHI-H3 to simulate atypically small decreases or large increases in both mean 294 and maximum snowfall extends to a wide area in the Baltic States, eastern 295 Sweden and south-central Finland. This speaks against local factors such as biases 296 in the Gulf of Finland ice cover as its main explanation.

298 Disregarding other factors, one would expect a negative correlation between the 299 changes in winter temperature and mean snowfall (i.e., larger decrease in snowfall 300 for larger warming). Table 2 confirms this expectation for Southern Finland, but 301 the correlation in Lapland is positive. This is apparently because the simulated 302 warming in Lapland increases with decreasing baseline mean temperature within 303 the ENSEMBLES data set $(r=-0.81)$; thus models with larger warming are less 304 prone to decreases in snowfall. Similarly, against naïve physical reasoning, 305 precipitation and snowfall changes are negatively correlated in Southern Finland. 306 In this case, the contradiction seems to be explained by a positive correlation 307 between the temperature and precipitation changes $(r=0.55)$. In both two regions, 308 however, models with less negative changes in mean annual snowfall also tend to 309 simulate less negative (or more positive) changes in annual maximum one-day 310 snowfall, although this correlation is only significant in Southern Finland.

312 It is important to recall that our sample only includes 12 model simulations. If a

313 larger ensemble of simulations were available, some of the correlations might be 314 substantially modified in magnitude, and even their sign might change, 315 particularly in those cases where the correlations are not significant at the 5\% risk 316 level (i.e., not marked in bold in Table 2).

\section{$317 \quad 3.3$ Seasonality of changes}

318 Seasonal cycles of the ensemble mean climate in Southern Finland are shown in 319 Fig. 4a. As compared with the years 1980-2010, the periods 2025-2055 and 20693202099 feature both higher temperature and (excluding March in 2025-2055) larger 321 precipitation throughout the year. However, the fraction of precipitation that falls 322 as snow is reduced substantially even in the middle of the winter, from a January323 February mean of $73 \%$ in $1981-2010$ to only $43 \%$ in $2070-2099$. Therefore, the 
324 mean snowfall decreases. The average monthly one-day snowfall maxima, which

325 are used in Fig. 4 to indicate the seasonality of heavy snowfall, are also reduced,

326 but less than the mean snowfall. By the years 2070-2099, the average January

327 maxima only decrease by $10 \%$, whereas the mean snowfall in the same month

328 decreases by nearly $30 \%$. Both the mean and the extremes decrease more in

329 earlier and later months. This is also reflected in the timing of the whole-winter

330 one-day snowfall maxima, which shows a stronger January peak in 2069-2099

331 (29\% of cases) than in 1980-2010 (23\%).

333 In Lapland (Fig. 4b), both temperature and precipitation increase slightly more 334 than in southern Finland. Because of the colder baseline climate, however, the 335 fraction of solid precipitation in the middle of the winter remains high, with a 336 January-February mean of $87 \%$ still in $2070-2099$. The decrease from the value 337 for 1981-2010 (96\%) only partly compensates the increase in total precipitation.

338 The mean snowfall therefore increases in these months, although it decreases until 339 November in autumn and again beginning from April in spring. Monthly 340 maximum one-day snowfall in Lapland in 1980-2010 shows a double peak, with 341 the main maximum in October-November and a secondary one in March-April. 342 As the simulated winters get milder during the 21 st century, the trough between 343 these nearly disappears, as snowfall maxima between December and March grow 344 larger but less heavy snowfall occurs in the autumn and late spring. Thus, just as 345 in Southern Finland, the annual one-day snowfall maxima occur increasingly 346 often in the coldest winter months.

348 Also indicated in Fig. 4 is the agreement between the individual model 349 simulations on the sign of the simulated changes. The agreement is strong for 350 temperature, with all 12 models simulating a warming in all months of the year in 351 both two areas, at least in 2069-2099 (closed circles). The same largely applies to

352 the decrease in the fraction of solid precipitation, in southern Finland to the 353 decrease in mean snowfall, and in Lapland to the increase in total precipitation. 354 The agreement on the changes in the other variables is less complete, but still 355 commonly statistically significant: when at least 10 out of the 12 models share the 356 same sign of change (as indicated by the open circles), the probability of reaching 357 this agreement by chance is at most $4 \%$. The least robust aspect of the model 
358 projections is the change in the timing of the annual snowfall maxima, particularly

359 in southern Finland.

3603.4 Dependence of snowfall changes on baseline mean

361 temperature

362 The geographical (Fig. 1) and seasonal variation (Fig. 4) of the simulated snowfall

363 changes together with their negative intermodel correlation with the baseline

364 winter temperatures (Table 2) all suggest a strongly temperature-dependent

365 response of snowfall to warming. A summary of this dependence is provided in

366 Figure 5. For each $1^{\circ} \mathrm{C}$ bin in the 1980-2010 monthly mean temperature, the

367 figure shows the $10^{\text {th }}, 50^{\text {th }}$ and $90^{\text {th }}$ percentiles of the changes in monthly mean

368 snowfall and average monthly maximum one-day snowfall from this period to

369 2069-2099, using data for all land grid boxes in the map domain of Fig. 1, all

370 models and all calendar months separately. The changes vary substantially even

371 for the same baseline temperature, partly because the focus on individual months

372 and grid boxes accentuates the effects of internal variability. Nevertheless, there is

373 a general shift from slight increases in mean and maximum snowfall for the

374 lowest temperatures to substantial decreases for milder baseline conditions. In

375 agreement with O'Gorman (2014), this shift is steeper for the mean snowfall than

376 for the monthly maximum snowfall, and the transition from a positive to a

377 negative median value occurs at a lower temperature for the former $\left(-11^{\circ} \mathrm{C}\right)$ than

378 for the latter $\left(-8^{\circ} \mathrm{C}\right)$. Figure $5 \mathrm{~b}$ also concurs with the results of de Vries et al.

379 (2014), who used an ensemble of KNMI RACMO2 RCM simulations to study

380 changes in snowfall under the RCP8.5 scenario in western Europe. Their Figure 3,

381 showing the change in DJF seasonal maximum snowfall against the DJF mean

382 baseline temperature, likewise indicates a shift from increases to decreases near a

383 baseline mean temperature of $-8^{\circ} \mathrm{C}$.

385 Despite a 10-15\% median increase in the monthly maximum one-day snowfall for 386 baseline temperatures below $-10^{\circ} \mathrm{C}$ (Fig. 5b), the annual maximum snowfall in 387 Lapland remains nearly unchanged (Fig. 1 and Table 2). Although heavier 388 snowfall events occur in the middle of the winter, this is compensated by 389 decreases in heavy snowfall in autumn and spring (Fig. 4b). 
$390 \quad 3.5$ How well can changes in snowfall be explained by

391 temperature change alone?

392 The relationship between the baseline winter temperatures and the snowfall

393 changes makes it tempting to cast a follow-up hypothesis: that the snowfall

394 changes can be understood solely as a result of the projected warming. Under this

395 hypothesis, the simulated future and baseline climates would share the same

396 quantitative relationship between the daily mean temperature and daily snowfall.

397 As more precipitation typically falls on mild than cold winter days, the increased

398 frequency of mild days should increase the total winter precipitation. On the other

399 hand, the more frequent occurrence of above-zero temperatures should increase

400 rainfall at the expense of snowfall.

402 To test the hypothesis, we calculated (for each model, month and grid box 403 separately) the frequency distribution of daily snowfall amounts for each $1{ }^{\circ} \mathrm{C}$ bin 404 in daily mean temperature, pooling together the data for 1980-2010 and 2069405 2099. Then, the expected change in annual mean snowfall was derived from the 406 daily mean temperatures in the two periods, replacing the simulated snowfall in 407 each day with the mean of the corresponding temperature bin. To estimate the 408 resulting change in snowfall extremes, surrogate time series of daily snowfall in 409 1980-2010 and 2069-2099 were created by randomly selecting, for each day, one 410 of the daily snowfalls in the actual temperature bin. This was repeated for 100 411 times and the resulting statistics of daily snowfall extremes were averaged.

413 The hypothesis is only partly successful. The resulting ensemble mean change in 414 annual mean snowfall from 1980-2010 to 2069-2099 (Fig. 6a) shows a pattern 415 similarity with the actual change (Figure 1, last panel in the third row), but with 416 systematically more positive values. If the relationship between temperature and 417 snowfall had remained constant, the total annual snowfall would have increased in 418 wide areas of northern Fennoscandia and the Scandinavian mountains. Further 419 south, the actual decrease in snowfall is larger than that predicted by the 420 hypothesis (Figs. 1 and 6b).

422 In the extreme upper end of the daily snowfall distribution, the temperature-based 423 prediction and the actually simulated changes are in better agreement (cyan vs. red 424 lines in Figs. 3b,d). For the ensemble mean change in the intensity of the 45 
425 strongest events, their difference is within 5\% in Southern Finland, and even less

426 in Lapland. For weaker snowfall events, however, the temperature-based

427 prediction indicates a too small decrease in snowfall intensity in Southern Finland

428 and an increase rather than a decrease in Lapland.

432 The temperature-snowfall relationship is analysed in more detail in Figure 7. We

433 focus here on the ensemble means but note that the intermodel agreement on the 434 sign of the changes is included in Fig. 7 in the same manner as in Fig. 4.

436 The first row in Fig. 7 shows, both for Southern Finland and Lapland, a decrease 437 in the annual number of cold days from 1980-2010 to 2069-2099. In Lapland, 438 however, daily mean temperatures close to or slightly below zero become more 439 common. As the average snowfall intensity is the largest for such days (second 440 row), this alone would act to increase snowfall. This explains the predicted 441 increase in total snowfall in northern areas in Fig. 6, although the snowfall gained 442 due to the larger frequency of slightly sub-zero temperatures is partly 443 compensated by the snowfall lost because of a greater decrease in the frequency of 444 colder days.

446 Yet, for the same daily mean temperature, less snow falls in the models in 20694472099 than in 1980-2010. In Southern Finland, this is the case regardless of 448 temperature. In Lapland, the mean snowfall amounts for the two periods converge 449 for temperatures higher than $-3^{\circ} \mathrm{C}$, but a substantial difference still occurs under 450 colder conditions. The difference between the two periods is of the same sign but 451 less pronounced for extreme snowfall, which is characterized in the third row of 452 Fig. 7 by the 98th percentile of snowfall for each temperature bin. In both 453 Southern Finland and Lapland, the peak of the 98th percentile near $-1{ }^{\circ} \mathrm{C}$ remains 454 virtually unchanged between 1980-2010 and 2069-2099. This apparently explains 455 why the change (or lack thereof) in the most extreme snowfall events can be 456 reasonably well predicted assuming an unchanged temperature-snowfall 457 relationship (Figs. 3b,d), although the same does not apply to total snowfall. 
459 The decrease in snowfall on cold days in a milder future climate parallels the 460 findings of de Vries et al. (2012). Using simulations made with the 461 ECHAM5/MPI-OM global climate model under the SRES A1B scenario, they 462 found a $20-50 \%$ decrease in the average snowfall of days with daily-mean 463 temperature below zero in large parts of western and central Europe from 19604641990 to $2070-2100$. They ascribed this decrease to the fact that, in the simulated 465 warmer future climate, sub-zero temperatures were more seldom reached under 466 circulation types that favor the occurrence of precipitation.

468 To study whether a similar mechanism might play a role in northern Europe, we 469 used local daily anomalies of sea level pressure (defined as deviations from local 470 30-year monthly means separately in 1980-2010 and 2069-2099) as a simple 471 indicator of circulation. On the average, although not always, higher sea level 472 pressure coincides with more anticyclonic conditions and less precipitation. On

473 the other hand, in northern Europe in winter, episodes of cyclonic flow are 474 typically milder than anticyclonic situations that often (although not always) have 475 less cloudy skies and larger radiative cooling. This suggests that, in a warmer 476 climate in which any fixed "low" value of daily mean temperature requires a 477 larger cold anomaly, these cold days should on the average have more positive 478 pressure anomalies and thus less snowfall.

480 For testing this scenario, daily anomalies of sea level pressure were binned with 481 temperature. Figures $7 \mathrm{~g}$-h confirm that days with low mean temperatures (i.e., 482 below $-2^{\circ} \mathrm{C}$ in Southern Finland and $-10^{\circ} \mathrm{C}$ in Lapland) have positive mean 483 pressure anomalies already in 1980-2010. In 2069-2098, the pressure anomalies 484 grow more positive, with all 12 models agreeing on this increase for a wide range 485 of temperatures $\left(0^{\circ} \mathrm{C}\right.$ to $-16^{\circ} \mathrm{C}$ in Southern Finland and $-5^{\circ} \mathrm{C}$ to $-26^{\circ} \mathrm{C}$ in Lapland). 486 Similar results were obtained when using absolute values of sea level pressure 487 instead of anomalies, although the intermodel agreement was slightly worse in 488 that case (not shown).

490 To study whether these temperature-dependent pressure changes are large enough 491 to explain the changes in mean snowfall, linear regression was used. For each grid 
492 box, model, month and temperature bin separately, regression coefficients linking

493 snowfall to pressure were calculated as

$$
a=\frac{N_{1} \operatorname{Cov}_{1}(P R S N, S L P)+N_{2} \operatorname{Cov}_{2}(P R S N, S L P)}{N_{1} \operatorname{Var}_{1}(S L P)+N_{2} \operatorname{Var}_{2}(S L P)}
$$

495 where $N_{1}$ and $N_{2}$ are the sample sizes for 1980-2010 and 2069-2099, $\operatorname{Cov}_{1 / 2}(P R S N$,

$496 S L P$ ) the corresponding covariances between pressure and snowfall, and

$497 \operatorname{Var}_{1 / 2}(S L P)$ the variances of sea level pressure. Then, the regression coefficients

498 were combined with the bin mean pressure change from 1980-2010 to 2069-2099

499 to estimate how this change affects the bin mean snowfall in 2069-2099. Two

500 regression-based estimates were derived, one using the full pressure change and

501 the other the change in pressure anomaly, thus omitting the 30-year monthly mean

502 pressure change between the two periods. These two options give similar results

503 (Fig. 8), because the time mean pressure changes in the ENSEMBLES data set are

504 small compared with the redistribution of pressure anomalies between different

505 temperature bins.

507 In Southern Finland, a substantial fraction of the decrease in the temperature508 binned mean daily snowfall is explained by the corresponding pressure increase 509 (Fig. 8a). This especially holds for temperatures close to and slightly below zero, 510 which are important for the total annual snowfall because of their large frequency 511 (Fig. 7a). In Lapland, the regression-based prediction is less accurate (Fig. 8b), as 512 it both severely underestimates the decrease in snowfall at temperatures below -

$51355^{\circ} \mathrm{C}$ and fails to reproduce the slight increase in snowfall at just below $0^{\circ} \mathrm{C}$. Thus, 514 changes in sea level pressure do contribute to the snowfall changes seen in Figs.

$5157 \mathrm{c}, \mathrm{d}$ but are not their sole explanation. This is not highly surprising, since the 516 local daily sea level pressure represents just one aspect of the atmospheric 517 circulation that might affect snowfall.

519 For reference, Fig. 7 also gives observational estimates for the years 1980-2010. 520 These are based on the E-OBS v10.0 data set, except for snowfall statistics that 521 were estimated from the E-OBS precipitation assuming the same temperature 522 dependence for the fraction of solid precipitation as on the average simulated by 523 the models. In brief, the model results and the observations are in qualitative 524 although not always quantitative agreement. The increase in mean and extreme 
525 snowfall with temperature is less steep for E-OBS than for the models, but this

526 might reflect a mismatch in timing between temperature and precipitation

527 observations. While the reported daily mean temperatures approximately represent

528 the 24-hour period ending at local midnight, the reporting period for precipitation

529 begins and ends at 06 UTC in the Nordic countries (8 AM local time in Finland in

530 winter). The irregularity in the observed increase in mean sea level pressure

531 towards lower temperatures in southern Finland is most likely due to the small

532 sample size near the low end of the distribution. For the model ensemble, the

533 sample size is less of an issue because data from 12 simulations were aggregated.

\section{4. Conclusions}

535 The changes in snowfall in the ENSEMBLES RCM simulations of 21st century 536 climate in northern Europe largely follow intuitive expectations and findings from

537 studies focussing on other areas. As the winters become shorter, snowfall in 538 autumn and spring months is reduced. In the middle of the winter, a more delicate 539 balance occurs between higher temperatures and larger precipitation, with the 540 latter (former) dominating in the coldest (milder) regions. On the average, the 541 boundary between increasing and decreasing mean snowfall coincides with the $54211^{\circ} \mathrm{C}$ isotherm in the baseline (1980-2010) monthly mean temperature (cf. $-10^{\circ} \mathrm{C}$ 543 in the global study of Krasting et al. (2013)), although with a substantial model, 544 month and location dependency. Even in the areas where snowfall is projected to 545 increase in the middle of the winter, the total annual snowfall is generally 546 projected to decrease, although the change is small in the coldest regions of 547 northern Europe.

549 Much less systematic change is simulated in the intensity of extreme daily 550 snowfall than in total annual snowfall. This agrees with O'Gorman (2014), and 551 can be qualitatively understood from the tendency of the heaviest snowfall events 552 to occur in similar conditions (marginally sub-zero temperatures with a favorable 553 circulation type) in both present and future climates. However, a larger fraction of 554 the heaviest snowfall events is simulated to occur near the middle of the winter in 555 the end of this century. A clear decrease in snowfall extremes is only simulated in 556 the mildest areas, where snowfall as a whole is becoming much less common. 
558 A smaller fraction of the snow in the simulated late $21^{\text {st }}$ century climate falls on

559 severely cold days, and a larger fraction on days with near-zero temperatures. Not

560 only do days with low temperatures become less common, but they also typically

561 have less snowfall for the same temperature than in the present-day climate.

562 Snow that falls at temperatures well below zero is generally drier and therefore

563 more prone to drift with wind than snow falling when the temperature is close to

564 the freezing point ( $\mathrm{Li}$ and Pomeroy 1997). As a result, it tends to be more difficult

565 to keep out of roads and railway tracks. On the other hand, the most slippery

566 conditions on pedestrian sidewalks are typically experienced on days when the

567 temperature is slightly below or crosses zero, particularly if precipitation falls in

568 some form (e.g. Ruotsalainen et al. 2004). In these respects, changes in the

569 combined temperature-snowfall climate are likely to have both positive and (in

570 colder areas, where temperatures close to zero are projected to increase in

571 frequency) negative consequences for traffic.

573 All aspects of future climate change have substantial quantitative uncertainty, 574 partly due to our limited ability to model the behavior of the climate system and 575 partly due to the unknown future anthropogenic and natural climate forcing. As is 576 most easily demonstrated by the projections of temperature change, the 577 ENSEMBLES simulations only cover a part of this uncertainty. The local NDJFM 578 warming in northern Europe only varies by about a factor of two between the 12 579 simulations (Table 2). By contrast, the latest IPCC projections for the global mean 580 temperature change during this century span a "likely" range of $0.3-1.7^{\circ} \mathrm{C}$ for the 581 lowest and $2.6-4.8^{\circ} \mathrm{C}$ for the highest RCP scenario (Collins et al. 2013), giving a 582 16-fold difference between the lowest and the highest estimate. By inference, the 583 changes in snowfall climate in the real future world might also be smaller or 584 larger than is suggested by the ENSEMBLES simulations. Nevertheless, the 585 qualitative aspects of our findings appear physically plausible and reasonably 586 robust. Only in the extreme case that changes in ocean currents lead to a cooling 587 of northern Europe (see Figure 12.9 of Collins et al. (2013) for a model simulation 588 in which this actually happens) would one anticipate snowfall changes of very 589 different character. 
591 In brief, the ENSEMBLES models simulate a moderate decrease in total snowfall 592 amount in northern Europe during this century but little change in the daily 593 extremes. This suggests that societies in the area will need to maintain their 594 capacity to cope with heavy snowfall even in the future, despite the expected 595 warming of winter climate.

\section{Acknowledgments}

597 The RCM simulations used in this study were obtained from the EU-FP6 project 598 ENSEMBLES (Contract number 505539). We also acknowledge the E-OBS 599 dataset from the ENSEMBLES project (http://ensembles-eu.metoffice.com) and 600 the data providers in the ECA\&D project (http://www.ecad.eu). This work was 601 supported by the Academy of Finland Centre of Excellence in Atmospheric 602 Science - From Molecular and Biological processes to the Global Climate 603 (project 272041). The constructive comments from two anonymous reviewers 604 helped to improve this article.

605

606 


\section{References}

608 Andræ U (2002) The Gävle 1998 snow storm. A case study of mesoscale snow 609 bands and a low level jet. EGS XXVII General Assembly, Nice, 21-26 April 610

611 Collins M, Booth BB, Bhaskaran B, Harris GR, Murphy JM, Sexton DMH, Webb 612 MJ (2010) Climate model errors, feedbacks and forcings: A comparison of

614 Collins M, Knutti R, Arblaster J, Dufresne J-L, Fichefet T, Friedlingstein P, Gao X, Gutowski WJ, Johns T, Krinner G, Shongwe M, Tebaldi C, Weaver AJ, Wehner M (2013) Long-term Climate Change: Projections, Commitments

Déqué M, Rowell DP, Lüthi

D, Giorgi F, Christensen JH, Rockel B, Jacob D,

de Vries H, Haarsma RJ, Hazeleger W (2014) On the future reduction in snowfall in western and central Europe. Clim Dyn 41: 2319-2330

de Vries H, Lenderink G, van Meijgaard E (2014) Future snowfall in western and central Europe projected with a high-resolution regional climate model ensemble. Geophys Res Lett 41: 4294-4299

Eisenberg D, Warner KE (2005) Effects of snowfalls on motor vehicle collisions, injuries, and fatalities. Amer J Public Health 95: 120-124

Haylock MR, Hofstra N, Klein Tank AMG, Klok EJ, Jones PD, New M (2008) A

633 Kapnick SB, Delworth TL (2013) Controls of global snow under a changed 
Karlsson C (2014) Statistisk av halkolyckor jämförd med Meteorologiska

Krasting JP, Broccoli AJ, Dixon KW, Lanzante JR (2013) Future changes in Northern Hemisphere snowfall. J Climate 26: 7813-7828

Lehtonen I (2015) Four consecutive snow-rich winters in Southern Finland: 2009/10-2012-2013. Weather 70: 3-8

Li L, Pomeroy JW (1997) Estimates of threshold wind speeds for snow transport using meteorological data. J Appl Meteor 36: 205-213

Nakićenović N, Swart R, Eds. (2000) Emission Scenarios. A Special Report of Working Group III of the Intergovernmental Panel on Climate Change, Cambridge University Press, 599 pp

O' Gorman P (2014) Contrasting responses of mean and extreme snowfall to climate change. Nature 512: 416-418

Räisänen J (2008) Warmer climate: less or more snow? Clim Dyn 30: 307-319

Räisänen J, Eklund J (2012) 21st Century changes in snow climate in Northern Europe: a high-resolution view from ENSEMBLES regional climate models. Clim Dyn 38: 2575-2591

Räisänen J, Ylhäisi JS (2014) $\mathrm{CO}_{2}$-induced climate change in northern Europe: CMIP2 vs. CMIP3 vs. CMIP5. Clim Dyn, doi: 10.1007/s00382-014-2440-x

Räisänen J, Hansson U, Ullerstig A, Döscher R, Graham LP, Jones C, Meier HEM, Samuelsson P, Willén U (2004) European climate in the late 21st century: regional simulations with two driving global models and two forcing scenarios. Clim Dyn 22: 13-31

Rális, ZA (1981) Epidemic of fractures during period of snow and ice. Bristish Medical Journal 282: 603-605 
664

665

666

667

668

669

670

671

672

673

674

675

676

677

678

679

680

681

682

683

684

685

686

687

688

689

690

691

692

Rogelj J, Meinshausen M, Knutti R (2012) Global warming under old and new scenarios using IPCC climate sensitivity range estimates. Nature Climate Change 2: 248-253

Ruotsalainen J, Ruuhela R, Kangas M (2004) Preventing pedestrian slipping accidents with help of a weather and pavement condition model. Walk21-V Ctities for People, Copenhagen, 9-11 June 2004. Available at http://www.walk21.com/papers/Copenhagen\%2004\%20Ruotsalainen\%20Pr eventing\%20pedestrian\%20slipping\%20ac.pdf

Savijärvi HI (2012) Cold air outbreaks over high-latitude sea gulfs. Tellus 64A: 12244

Seneviratne SI, Nicholls N, Easterling D, Goodess CM, Kanae S, Kossin J, Luo Y, Marengo J, McInnes K, Rahimi M, Reichstein M, Sorteberg A, Vera C, Zhang X (2012) Changes in climate extremes and their impacts on the natural physical environment. Managing the Risks of Extreme Events and Disasters to Advance Climate Change Adaptation, CB Field et al., Eds., Cambridge University Press, pp 109-230

Tilastokeskus (2014) Suomen tilastollinen vuosikirja 2014 (Statistical Yearbook of Finland 2014; in Finnish). Edita Prima Oy, Helsinki, 692 pp. Available at http://www.stat.fi/tup/julkaisut/tiedostot/julkaisuluettelo/yyti_stv_201400_2 014_10374_net.pdf

van den Besselaar EJM, Haylock MR, van der Schrier G, Klein Tank AMG (2011) A European daily high-resolution observational gridded data set of sea level pressure. J Geophys Res 116: D11110

van der Linden P, Mitchell JFB, Eds. (2009) ENSEMBLES: Climate Change and its Impacts: Summary of research and results from the ENSEMBLES project. Met Office Hadley Centre, FitzRoy Road, Exeter EX1 3PB, UK, $160 \mathrm{pp}$

van Vuuren DP, Edmons J, Kainuma M, Riahi K, Thomson A, Hibbard K, Hurtt GC, Kram T, Krey V, Lamarque J-F, Masui T, Meinshausen M, 


\section{Tables}

697 Table 1. The model simulations used in this study

698

\begin{tabular}{llll}
\hline Driving GCM & RCM & Institution & Shorthand \\
\hline ARPEGE_RM5.1 & Aladin & CNRM & CNRM-A \\
ECHAM5-r3 & HIRHAM5 & DMI & DMI-E5 \\
& RACMO2 & KNMI & KNMI-E5 \\
& REMO & MPI & MPI-E5 \\
& RCA3 & SMHI & SMHI-E5 \\
HadCM3Q3 & RCA3 & SMHI & SMHI-H3 \\
& HadRM3Q3 & Met Office & METO-H3 \\
HadCM3Q0 & CLM & ETHZ & ETHZ-H0 \\
& HadRM3Q0 & Met Office & METO-H0 \\
HadCM3Q16 & RCA3 & C4I & C4I-H16 \\
& HadRM3Q16 & Met Office & METO-H16 \\
BCM & RCA3 & SMHI & SMHI-BCM \\
\hline
\end{tabular}

699

700 The first column indicates the driving global climate model, the second the

701 regional climate model and the third the institution that conducted the simulations,

702 using model and institution acronyms that follow the ENSEMBLES Research

703 Theme 3 web page (http://ensemblesrt3.dmi.dk/). HadCM3Q3, HadCM3Q0 and

704 HadCM3Q16 are three members of the HadCM3 perturbed-parameter ensemble

705 (Collins et al. 2010) with low, intermediate and high sensitivity to increasing

706 greenhouse gas concentrations, respectively. HadRM3Q3, HadRM3Q0 and

707 HadRM3Q16 are the corresponding versions of the HadRM3 RCM. The last

708 column gives the shorthand notations used in this article

709

710 
711 Table 2. Area means for the individual model simulations in Southern Finland 712 (SF) and Lapland (L)

713

\begin{tabular}{|c|c|c|c|c|c|}
\hline Simulation & $\begin{array}{l}\mathrm{T}_{\mathrm{CTRL}} \\
\mathrm{SF} / \mathrm{L}\end{array}$ & $\begin{array}{l}\Delta \mathrm{T} \\
\mathrm{SF} / \mathrm{L}\end{array}$ & $\begin{array}{l}\Delta \mathrm{PR} \\
\mathrm{SF} / \mathrm{L}\end{array}$ & $\begin{array}{l}\triangle \mathrm{PRSN} \\
\mathrm{SF} / \mathrm{L}\end{array}$ & $\begin{array}{l}\triangle \mathrm{MaxPRSN} \\
\mathrm{SF} / \mathrm{L}\end{array}$ \\
\hline CNRM-A & $-3.7 /-14.4$ & $\underline{2.7 / 5.9}$ & $\underline{8} / 14$ & $-38 /-11$ & $-5 /-5$ \\
\hline DMI-E5 & $-2.8 /-8.9$ & $4.1 / 4.4$ & $22 / 33$ & $-44 /-14$ & $-20 / 1$ \\
\hline KNMI-E5 & $-2.8 /-7.6$ & $3.7 / 4.1$ & $21 / \underline{9}$ & $-37 /-25$ & $-13 / \underline{-10}$ \\
\hline MPI-E5 & $\underline{-2.2} / \underline{-6.9}$ & $3.6 / \underline{4.0}$ & $15 / 9$ & $-35 /-25$ & $-9 /-4$ \\
\hline SMHI-E5 & $-2.9 /-8.7$ & $4.0 / 4.7$ & $23 / 19$ & $-53 /-28$ & $-19 /-6$ \\
\hline SMHI-H3 & $\underline{-6.9 /-14.6}$ & $4.1 / 5.6$ & $18 / 22$ & $\underline{-27 /-10}$ & $\underline{12 / 2}$ \\
\hline METO-H3 & $-5.9 /-12.8$ & $3.9 / 4.7$ & $17 / 18$ & $-36 /-10$ & $-6 / 3$ \\
\hline ETHZ-H0 & $-6.1 /-12.2$ & $5.0 / 5.3$ & $19 / 27$ & $-43 /-11$ & $-6 / 5$ \\
\hline METO-HO & $-6.5 /-13.5$ & $5.0 / 5.5$ & $10 / 27$ & $-48 /-10$ & $-5 / \underline{9}$ \\
\hline C4I-H16 & $-2.7 /-8.6$ & $4.7 / 5.4$ & $\underline{30 / 36}$ & $-58 / \underline{-29}$ & $-14 / 4$ \\
\hline METO-H16 & $-4.2 /-10.3$ & $\underline{5.5 / 5.9}$ & $27 / 28$ & $\underline{-59 /-23}$ & $-16 / 3$ \\
\hline SMHI-BCM & $-4.2 / \underline{-17.1}$ & $3.4 / 7.1$ & $11 / 22$ & $-45 /-\underline{-7}$ & $-11 / 0$ \\
\hline Mean & $-4.2 /-11.3$ & $4.1 / 5.2$ & $18 / 22$ & $-44 /-17$ & $-9 / 0$ \\
\hline $\mathrm{SD}$ & $1.7 / 3.3$ & $0.8 / 0.9$ & $7 / 9$ & $10 / 8$ & $9 / 5$ \\
\hline $\mathrm{r}(\triangle \mathrm{PRSN})$ & $-0.31 /-\mathbf{0 . 8 6}$ & $\mathbf{- 0 . 5 9} / 0.48$ & $-0.56 / 0.06$ & $1.00 / 1.00$ & $\mathbf{0 . 7 1} / 0.42$ \\
\hline $\mathrm{r}(\triangle \mathrm{Max} \mathrm{PRSN})$ & $-\mathbf{0 . 7 2} /-0.37$ & $-0.16 / 0.36$ & $-0.16 / \mathbf{0 . 7 5}$ & $0.71 / 0.42$ & $1.00 / 1.00$ \\
\hline
\end{tabular}

714

$715 T_{C T R L}=$ NDJFM mean temperature in 1980-2010 $\left({ }^{\circ} \mathrm{C}\right), \Delta T=$ NDJFM temperature

716 change to $2069-2099\left({ }^{\circ} \mathrm{C}\right), \triangle P R=$ NDJFM precipitation change $(\%), \triangle P R S N=$

717 change in mean annual snowfall (\%), $\triangle M a x P R S N=$ change in mean annual one-

718 day maximum snowfall (\%). The highest and lowest values in the ensemble are

719 underlined. $S D=$ standard deviation. $r(\triangle P R S N)$ and $r(\triangle M a x P R S N)=$ Pearson

720 product-moment correlation with $\triangle P R S N$ and $\triangle M a x P R S N$. Statistically significant

721 correlation coefficients (5\% level, two-sided test, $|r|>0.576$, treating the 12

722 simulations as independent samples of a normal distribution although this is not

723 strictly true) are given in bold 


\section{Figures with captions}
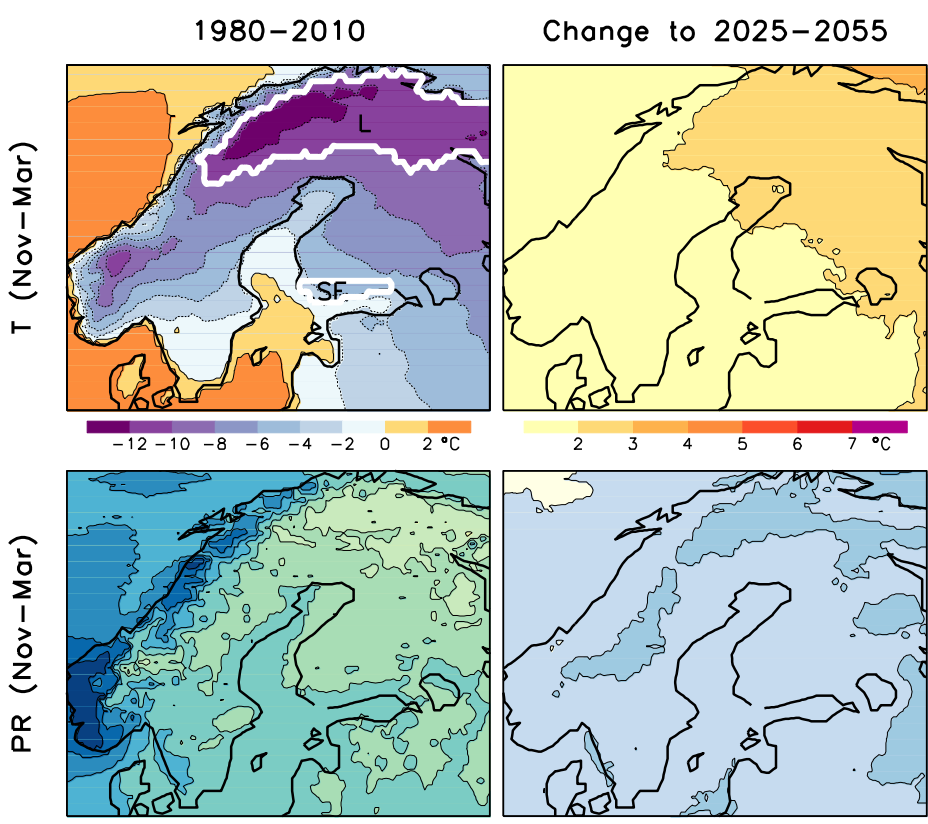

Change to $2069-2099$
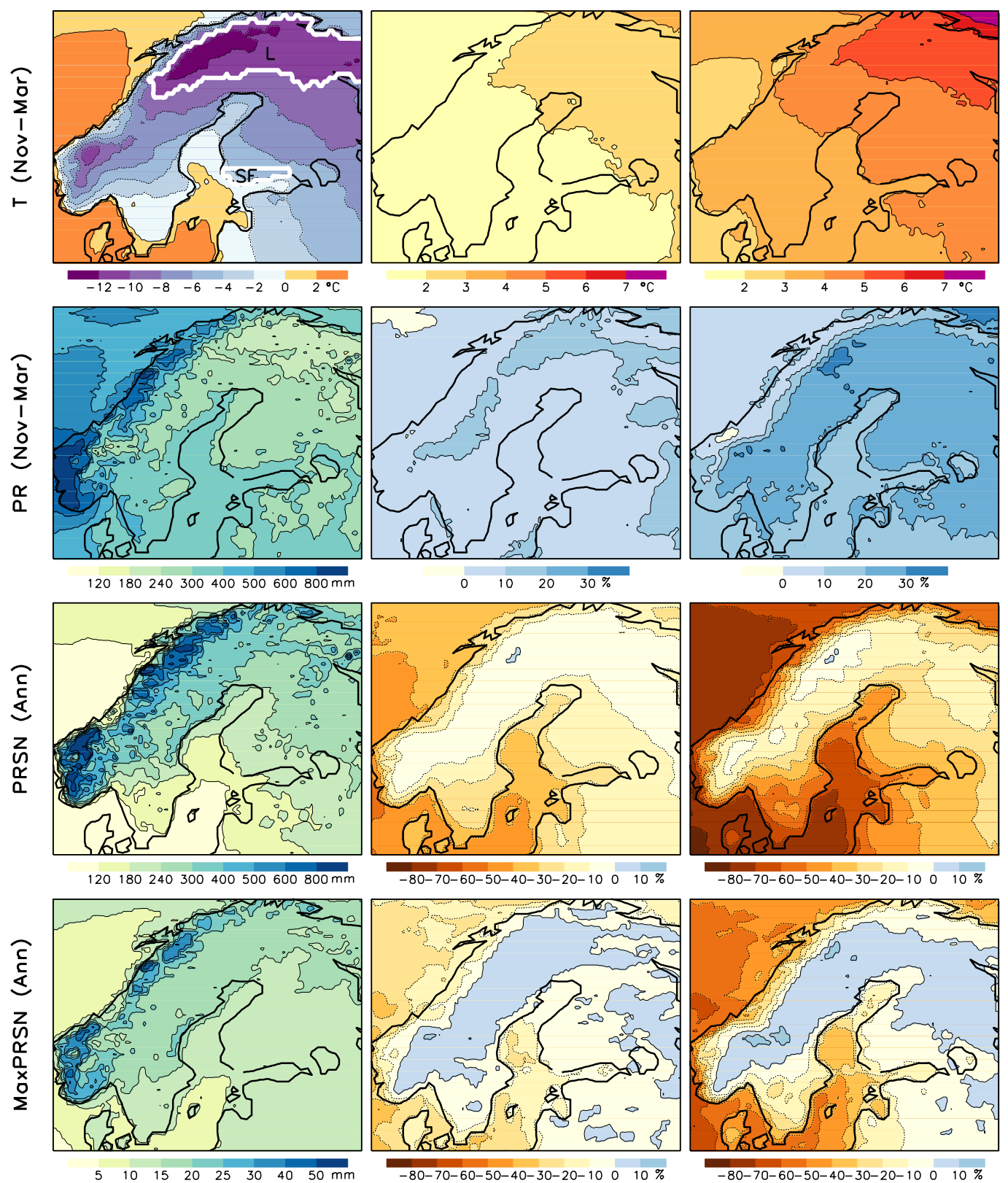

Fig. 130 -year ensemble mean climate in northern Europe in the years 1980-2010

728 (left) and its change to 2025-2055 (middle) and 2069-2099 (right). Rows 1-2:

729 November-March mean temperature and precipitation. Rows 3-4: Water

730 equivalents of mean annual snowfall and average annual maximum one-day

731 snowfall. The areas denoted as Southern Finland (SF) and Lapland (L) are

732 outlined in the top-left panel 

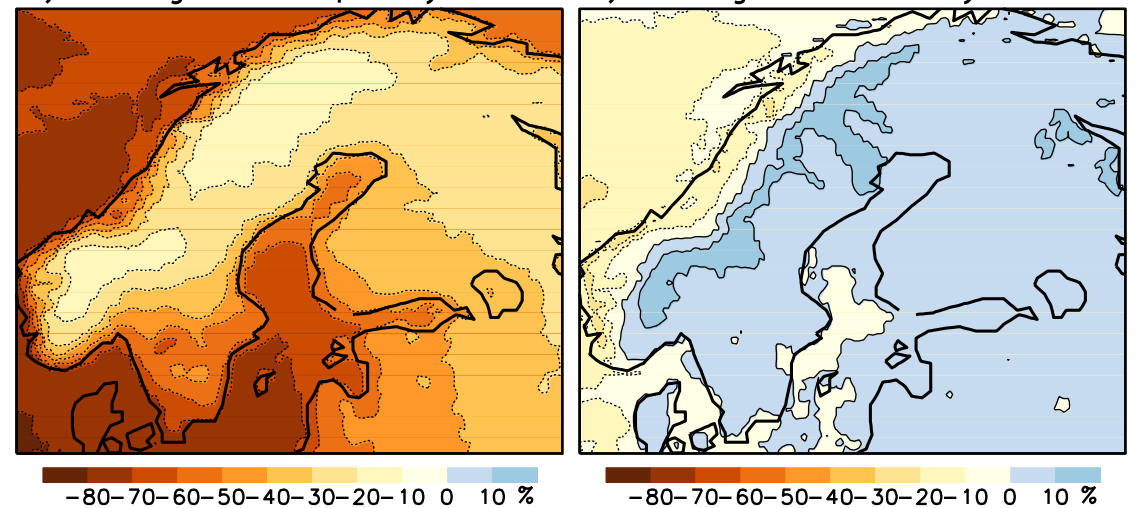

733

Fig. 2 Ensemble mean changes (a) in the frequency of days with at least $1 \mathrm{~mm}$

735 WE of snowfall and (b) in the average snowfall of these days from 1980-2010 to

$736 \quad 2069-2099$ 

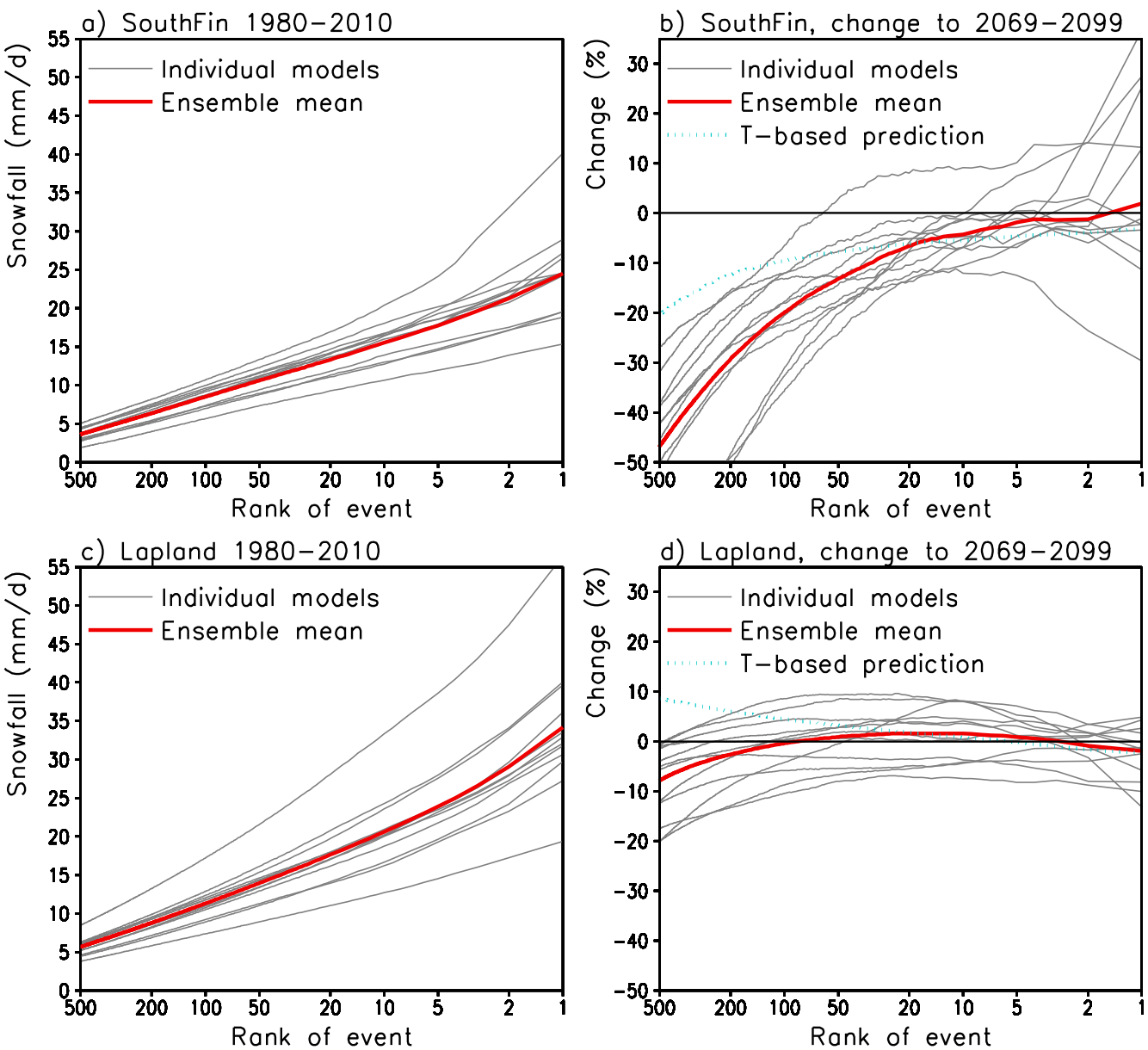

Fig. 3 (a) The intensity of the strongest 500 daily snowfall events in the years

740 1980-2010, as averaged over Southern Finland. The thick red line represents the

741 ensemble mean and the thin grey lines the 12 individual simulations. (b) As (a),

742 but for changes in snowfall intensity from 1980-2010 to 2069-2099. The dotted

743 cyan line shows a temperature-based prediction for the ensemble mean change

744 (Section 3.5). (c,d) As (a,b) but for Lapland 
a) Southern Finland
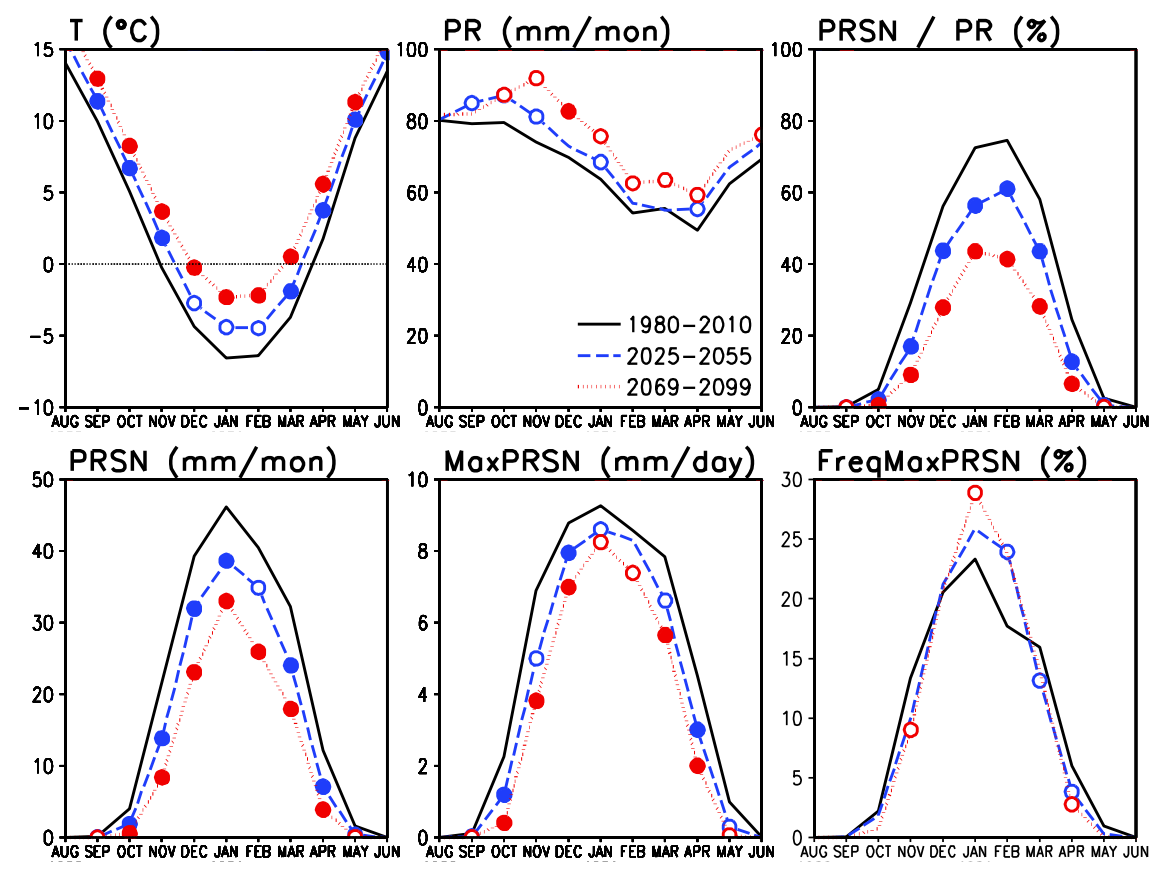

b) Lapland
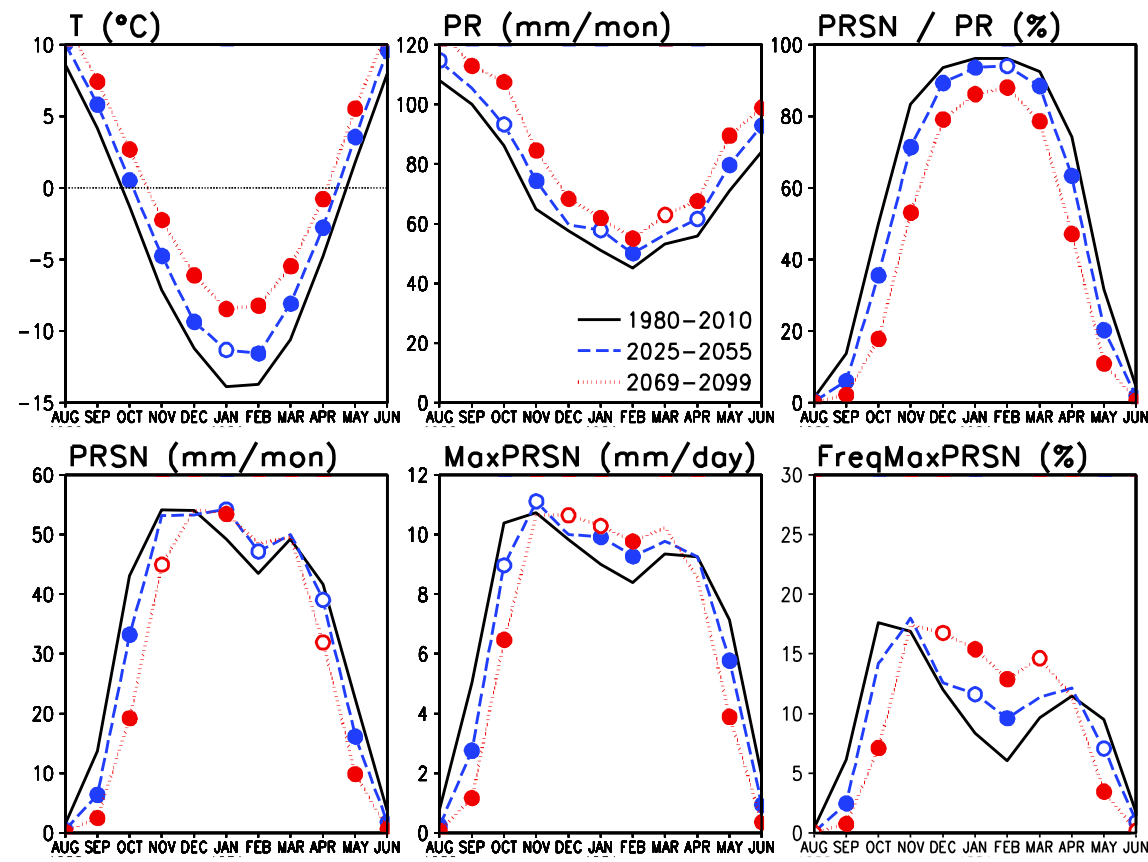

746 Fig. 4 30-year mean seasonal cycles (August to June) of ensemble mean climate

747 in (a) Southern Finland and (b) Lapland in the years 1980-2010 (black), 2025-

7482055 (blue) and 2069-2099 (red). $T=$ mean temperature, $P R=$ mean total

749 precipitation, $P R S N=$ mean snowfall, $\operatorname{Max} P R S N=$ mean monthly one-day

750 maximum snowfall, FreqMaxPRSN = frequency distribution for the month in

751 which the winter maximum daily snowfall occurs. Closed (open) circles indicate

752 months in which all 12 (10 or 11) models agree on the sign of the change relative

753 to $1980-2010$ 
a) $\triangle$ PRSN

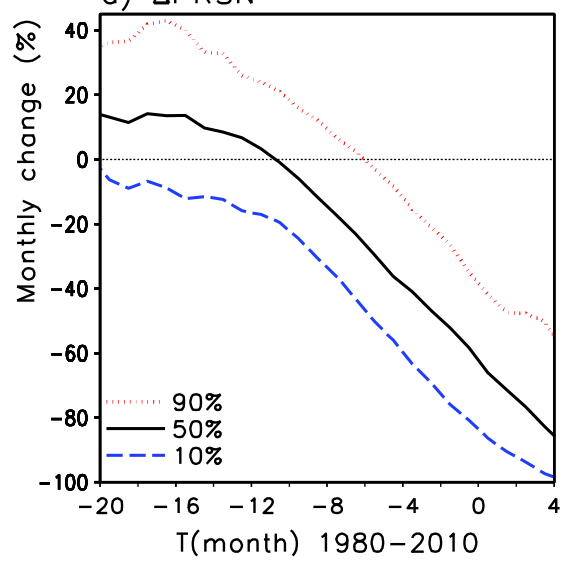

b) $\triangle$ MaxPRSN

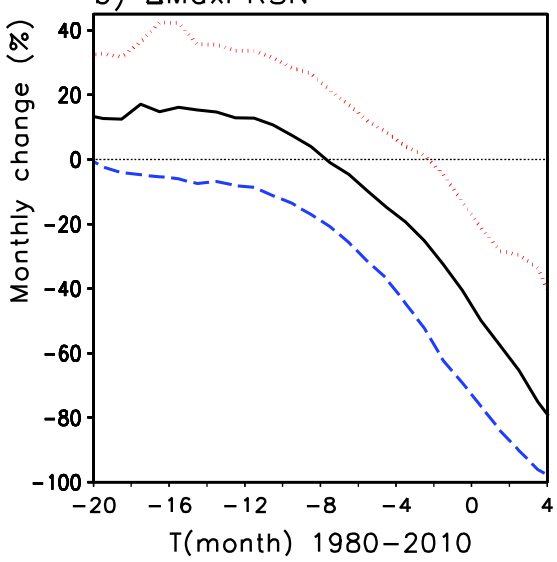

Fig. 5 Relationship of the baseline monthly mean temperature with changes in (a)

756 mean snowfall and (b) average monthly maximum one-day snowfall from 19807572010 to $2069-2099$. In both cases, the $10 \%, 50 \%$ and $90 \%$ quantiles are given, 758 using data for all 12 models, all calendar months and all land grid boxes in the 759 map area of Fig. 1 
a) Explained by temperature change

b) Unexplained by temperature change

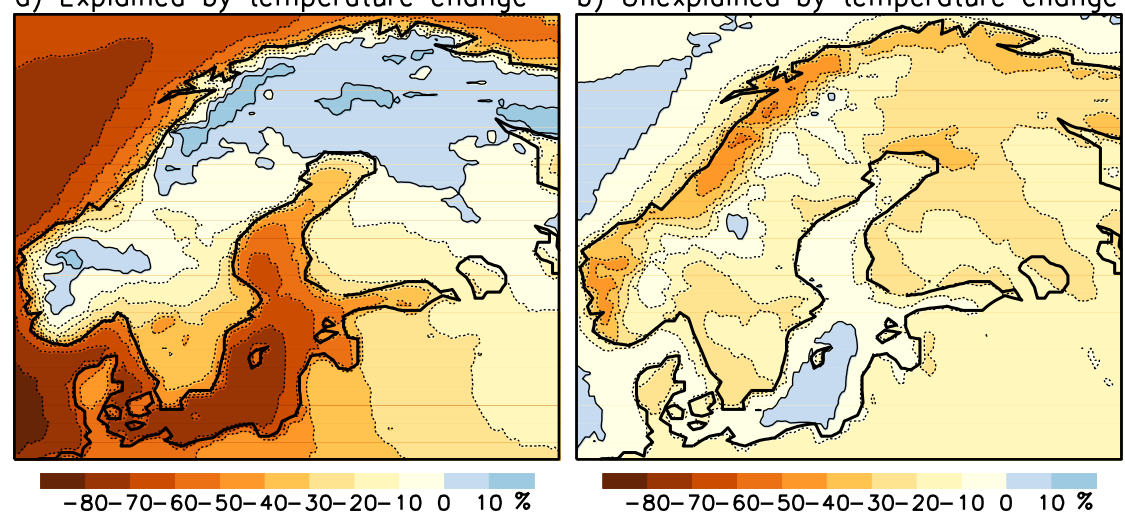

760

761 Fig. 6 (a) Change in annual and ensemble mean snowfall from 1980-2010 to

762 2069-2099, predicted by assuming the same relationship between daily mean

763 temperature and snowfall in the two periods. (b) The difference between the actual

764 change and the temperature-based prediction 
Southern Finland
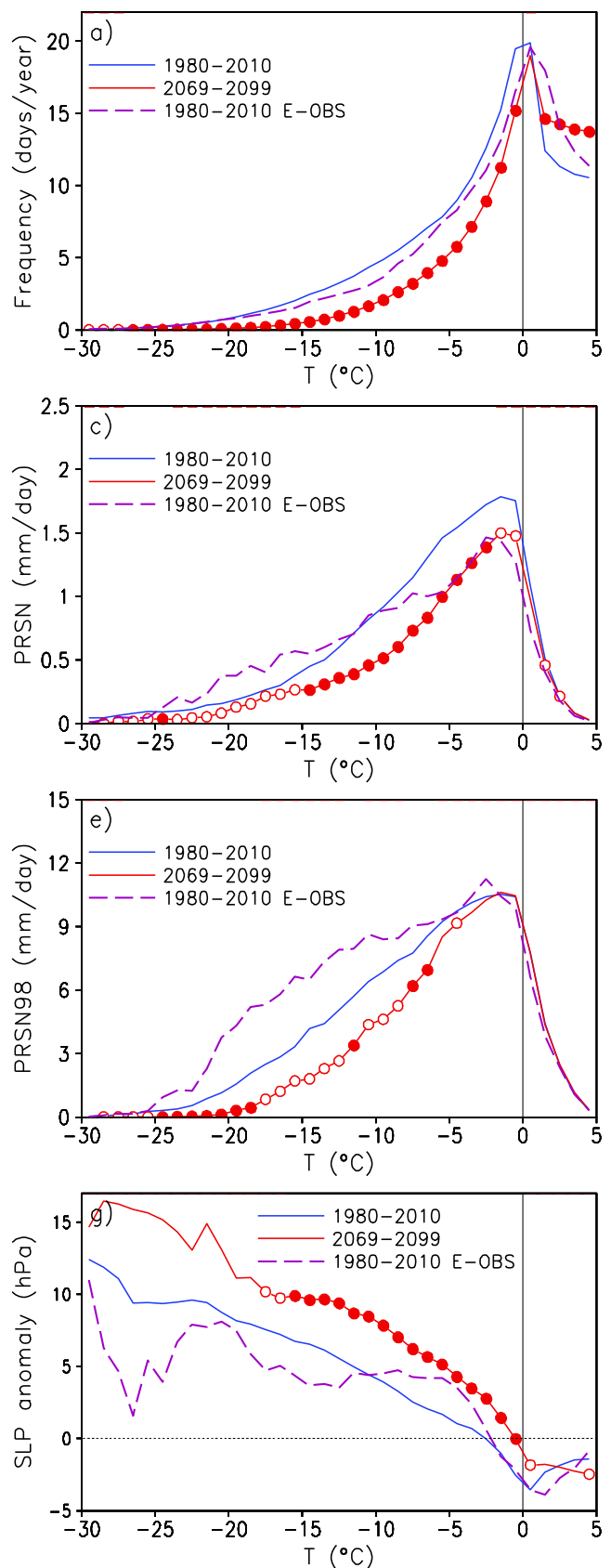

Lapland
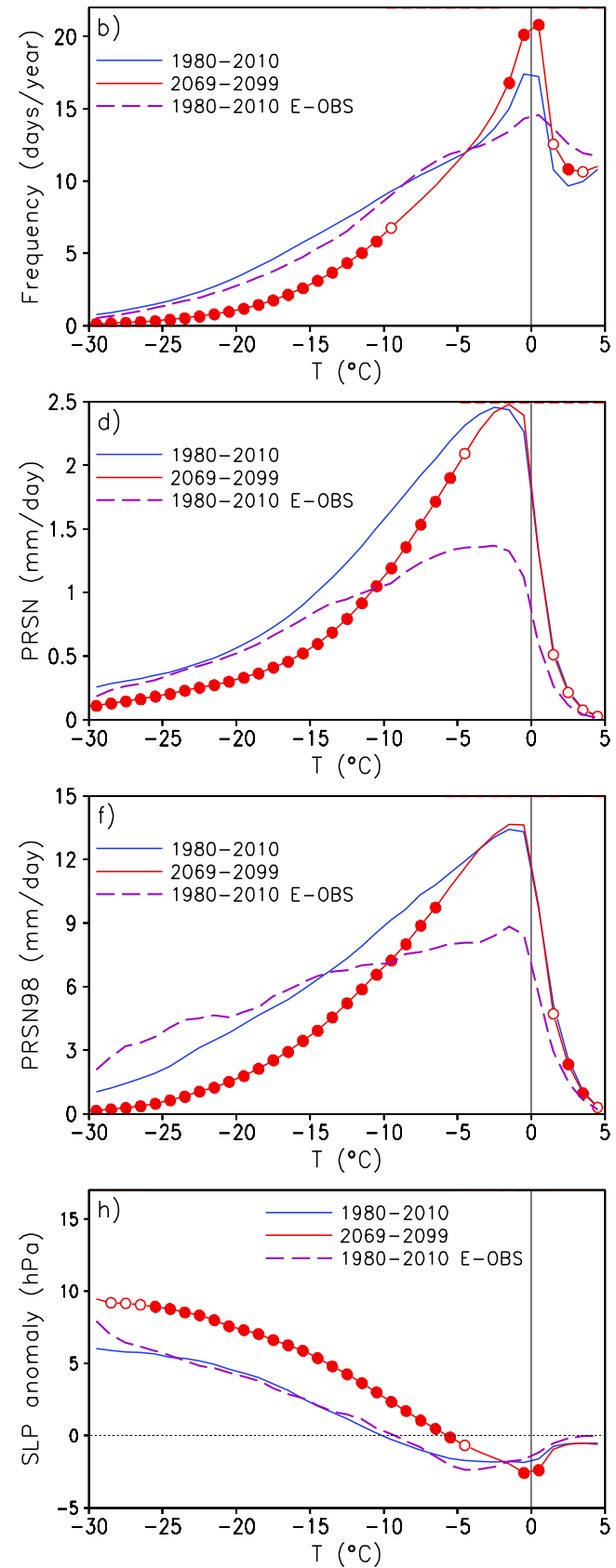

Fig. 7 Ensemble mean climate statistics as a function of daily mean temperature, using data from all 12 models, the whole year, and all grid boxes either in

768 Southern Finland (left) or Lapland (right). Row 1: average annual frequency 769 distribution of temperature (days per year for each $1^{\circ} \mathrm{C}$ bin). Row 2: mean daily 770 snowfall. Row 3: $98^{\text {th }}$ percentile of daily snowfall. Row 4: anomaly in mean sea 771 level pressure. Results are shown for the model simulations in 1980-2010 (blue) 772 and 2069-2099 (red) and for the E-OBS analysis in 1980-2010 (dashed purple;

773 snowfall statistics for E-OBS were estimated from total precipitation). Closed 774 (open) circles indicate temperature bins in which all 12 (10 or 11) models agree on the sign of the change from 1980-2010 to 2069-2099 

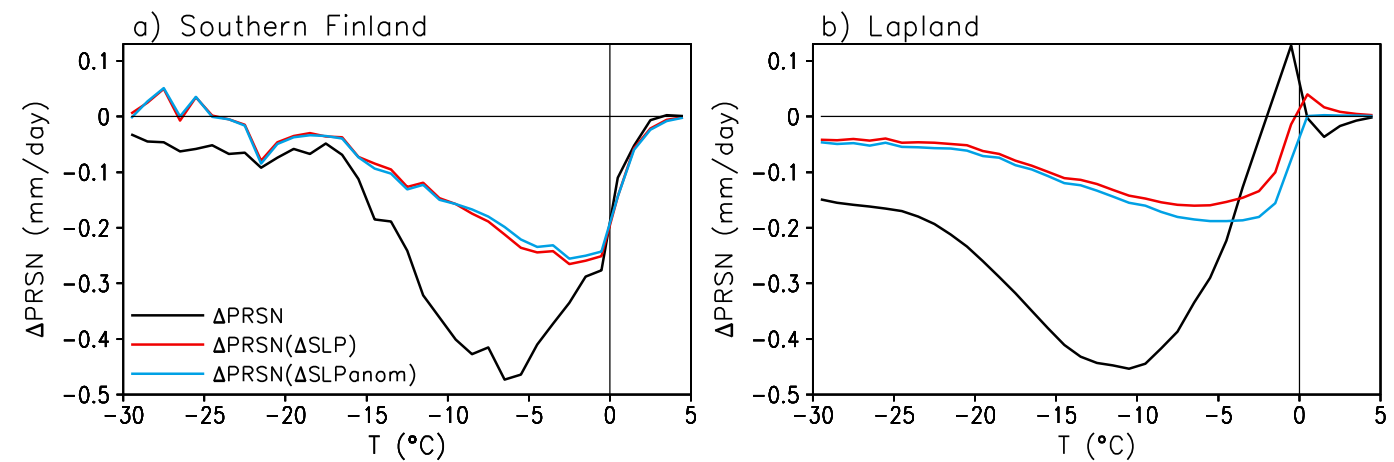

777 Fig. 8 Black: changes in mean daily snowfall as a function of temperature from

778 1980-2010 to 2069-2099 in (a) Southern Finland and (b) Lapland, averaged in the

779 same way as in Fig. 7. Red and blue: regression-based estimates for the snowfall

780 change explained by changes in sea level pressure, either including (red) or

781 excluding (blue) the time mean pressure change between the two periods 